\title{
A School-Based Intervention Addressing Peer Perceptions of Disabilities
}

\author{
Michelle Gamber ${ }^{1, ~ *, ~ C a t h y ~ S h a n h o l t z ~}{ }^{2}$ \\ ${ }^{1}$ School of Health Professions, Division of Public Health, Shenandoah University, Winchester, Virginia, USA \\ ${ }^{2}$ School of Health Professions, Division of Occupational Therapy, Shenandoah University, Winchester, Virginia, USA
}

Email address:

mgamber@su.edu (M. Gamber), cshanhol2@su.edu (C. Shanholtz)

${ }^{*}$ Corresponding author

To cite this article:

Michelle Gamber, Cathy Shanholtz. A School-Based Intervention Addressing Peer Perceptions of Disabilities. International Journal of Elementary Education. Vol. 9, No. 1, 2020, pp. 15-19. doi: 10.11648/j.ijeedu.20200901.13

Received: March 7, 2020; Accepted: March 23, 2020; Published: April 7, 2020

\begin{abstract}
The Individuals with Disabilities Education Act (IDEA), enacted in 1975, mandates a free and public education for children with disabilities. Yet, research shows that children with disabilities still do not always feel accepted in the public school system, and there are many improvements needed for an inclusive environment to be fully realized. Better awareness of peers with disabilities in the school system allows for a positive classroom environment and learning experience for all children. Increased awareness provides the possibility of school systems to modify their curriculum to better suit individuals with disabilities. Disability awareness interventions can improve children's knowledge about peers with disabilities and can be approached in many ways. The purpose of this study was to measure student attitudes and perceptions of individuals with disabilities in a primary school setting in rural Virginia. Results from the study indicated a positive change in the perceptions and attitudes of participants after administration of the Whitehorse Disability Kit lessons over the course of four weeks. This study supports previous similar research as the attitudes and perceptions of children with disabilities increased after implementing four weeks of lesson plans. This study demonstrates the positive impact of incorporating disability awareness programs in the school system.
\end{abstract}

Keywords: Disability, Inclusion, Schools, Peer Perceptions, Occupational Therapy

\section{Introduction}

According to the World Health Organization, approximately " $15 \%$ of the world's population lives with some form of disability, of whom $2-4 \%$ experience significant difficulties in functioning" [1]. The Individuals with Disabilities Education Act (IDEA), enacted in 1975, mandates a free and public education for children with disabilities [2]. Yet, research shows that children with disabilities still do not always feel accepted in the public school system, and there are many improvements needed for an inclusive environment to be fully realized [3]. MacArthur and Kelly [2], illustrated that students with disabilities recalled experiences where teachers assumed, they could not handle the curriculum, taught age inappropriate skills, secluded them from eating lunch with other students, and undermined their skills in the regular classroom setting. As a result, typically developing students then mimicked the teacher's attitudes and engaged similar types of behaviors with their peers with disabilities such as: neglecting, decrying, and avoiding interaction with their peers with disabilities.

Most typically developing students tend to not understand inclusive education and react by avoiding their peers with disabilities or engage in bullying behavior [4]. Lack of knowledge, coupled with negative attitudes and perceptions of children and peers with disabilities remains a challenge in the school setting $[5,6]$. Schools are encouraged to contribute to educating all students about inclusive environments as well as providing more opportunities for typically-developing students to interact with their peers with disabilities [4]. However, how to effectively accomplish this in schools settings is not universally understood or implemented at the school administration level. Additionally, more awareness is needed in order for peers to have a better 
understanding of individuals with disabilities to create a more inclusive and positive learning environment.

Better awareness of peers with disabilities in the school system allows for a positive classroom environment and learning experience for all children. Increased awareness provides the possibility of school systems to modify their curriculum to better suit individuals with disabilities. Novak and Barthelheim [7] found that general education students felt an increase in the desire to work with peers with disabilities where cooperative learning conditions were present versus classrooms where competitive learning conditions existed. In classrooms where teachers did not encourage or teach positive interactions, students with disabilities reported experiencing teasing, prejudice, stereotyping, and even rejection [7].

Disability awareness interventions can improve children's knowledge about peers with disabilities and can be approached in many ways [5]. Additionally, teachers and adults can also benefit from disability awareness programs [8]. The results from Campbell, Gilmore and Cuskelly [8], led to the student teachers becoming more aware of disability, more positive attitudes towards disability, and increased ease when interacting with people with disability. Disability awareness leads to positive attitudes between students and an inclusive society as well as a decrease in levels of bullying, which carries on throughout a child's lifetime [9].

The purpose of this study was to measure student attitudes and perceptions of individuals with disabilities in a primary school setting in rural Virginia. There are a number of interventions that have been used to implement children's increased understanding of individuals with disabilities. Yet, there is a paucity of evidence in the literature to support whether or not these interventions do improve perceptions and behaviors toward those with disabilities. For this study, the Whitehorse Disability Kit tool was used as the intervention to enhance children's knowledge about individuals with disabilities and decrease misconceptions [10]. The overall goal was to understand if the Whitehorse Disability Kit positively impacted student perceptions and attitudes toward their peers with disabilities within the school system.

\section{Background}

Disability is considered a physical or intellectual condition that affects a person's daily life [11]. Intellectual disability is defined as someone who has an IQ of 70 or less and it relates to a lack in social, cognitive, and adaptive domains [12]. Physical disability is an impairment in a person's physical functions, mobility, and dexterity impairments that impacts their life [13]. Children that have physical or intellectual disabilities face many obstacles that could include isolation and exclusion amongst their peers in the school system and in society [15]. De Boer, Pijl, \& Minnaert [15], noted that "specific training is needed for children without disabilities in order for them to interact with peers with disabilities in a positive and age-appropriate manner" [15]. Previous studies have examined attitudes and beliefs of individuals without disability towards those with disabilities while also incorporating various awareness intervention programs $[3,5$, $6,16,17,18]$. Within many of the interventions, attitudes towards people with disability are mixed, but many of these studies find that students face bullying and social isolation due to disability. As a result, awareness interventions programs have been implemented to promote an inclusive environment. Within these studies, several themes surrounding disability emerged that are important areas to address including attitudes, inclusion, and awareness.

\subsection{Inclusion}

Inclusive education has the ability to change and improve individuals' attitudes towards those with disabilities while also increasing socialization between individuals with and without disabilities [3, 19]. Inclusion includes, but is not limited to, students with disabilities and typically developing students in classroom learning environments together. With inclusive education, some individuals with disabilities may be in special education classrooms, but most individuals would be integrated mainstream classrooms with their peers [3]. Lindsay \& McPherson [3]. interviewed children and adolescents with disabilities in integrated classrooms in order to find suggestions on ways to improve social inclusion. Disclosing the individual's condition and creating awareness of disability were important for improving inclusion in the classroom. One youth with a disability stated, "the school system needs to understand that we're the same as everyone else and we want the same things in life...We need to improve exposure to people with disabilities.... You know, it's just natural and I'm happy the way I am" [3]. It is important for children to understand and be exposed to information that everyone is different and even if someone has a disability they are still a person who is entitled to the same opportunities and to be treated with respect. By incorporating inclusion classrooms from an early age, it allows the following to occur:

1. Acceptance

2. Social cohesion.

3. Decreases the chances that peers will look down upon individuals with a disability later in life.

4. Promotes positive self-awareness of those with disabilities.

5. Encourages positive social interactions amongst peers.

By exposing children to disability awareness and acceptance messages early on, this decreases the chances that peers will look down upon an individual with a disability later in life [20]. Inclusive environments, especially in the school system, have the opportunity to promote positive awareness of those with disabilities and can encourage positive social interactions amongst peers. However, how this inclusive environment is structured is important to lead to optimal success in this area. As stated by Hartley and colleagues [21], "It is not enough to place students with disabilities in same physical classroom... there is need to further define and support the social integration of students with disabilities within the broader social structure of the school" 


\subsection{Bullying and Social Rejection}

Being a child or youth with a disability in an inclusive classroom increases the risk of being bullied and socially rejected [3]. Research has shown that bullying is more likely to occur when a child has a disability when compared to their “typically developing" peer [21]. Qualities linked to students being victimized include individuals with a lack of social skills, lack of independence, few friends and overall observable differences [21]. These qualities are often seen in individuals with disabilities, making them a perfect target for bullying. By creating a social environment where peers are exposed to peers with disabilities in a positive way, and where they interact with peers with disabilities on a regular basis, not only allows students to build friendships with all their peers, but it also fosters the development of social skills [3].

\subsection{Awareness Interventions}

There are many disability awareness interventions that have been created and discussed in the literature, but what makes an intervention successful is not as commonly known in the knowledge base. However, there are some reviews that have been undertaken to draw on. Lindsay and Edwards [5] completed a systematic review on disability awareness interventions in the literature. From their review, different interventions were classified into five broad types such as: social contact, simulation, curriculum, multimedia curriculum, and multiple components. Within Lindsay and Edward's review [5], thirty-four other studies showed an improvement in attitudes towards and/or acceptance of peers with disabilities with the use of various intervention types. Different schools implemented interventions and disability awareness programs $[9,16]$. These studies used a cognitivebehavioral approach which included contact with people with disabilities leading to the knowledge, attitudes, and acceptance of disability increasing after the intervention. From these studies, overall students reported enjoying the activities and had an overall positive attitude about the programs and the information they were learning.

Based on the lack of systematic evaluations of disability awareness interventions, there is an identified need for a reliable assessment tool to measure attitudes toward children with disability. As a result, the current study utilized the Whitehorse Disability Kit which currently does not have evidence to support its use within public elementary schools. The current study explored how the Whitehorse Disability Kit changes student's attitudes and awareness towards peers with disability through the use of guided worksheets and activities.

\section{Methods}

\subsection{Design}

The research was conducted at a local elementary school in Winchester, VA. The study was organized with a pretest- posttest design method using the Chedoke-McMaster Attitudes Towards Children With Handicaps (CATCH) assessment. The CATCH is a reliable tool for assessment $[22$, 23]. The CATCH assesses children's attitudes including affective, behavioral, and cognitive measures. Bossaert and Petry examined reliability and validity of $\mathrm{CATCH}$ and within the study, they noted that the measure was found to be reliable, showing acceptable internal consistency $(\alpha=.90)$ and test-retest stability.

The students took the CATCH assessment, which uses a Likert scale to ask about their current perceptions of students with disabilities. Then, activities from the Whitehorse Learning Disability Kit, were administered after the initial CATCH assessment questionnaire was completed. These activities educated the students about perceptions of individuals with disabilities over a series of 4 different time points over the course of two months. Following the completion of the Whitehorse Disability Kit activities, the $\mathrm{CATCH}$ assessment was readministered to analyze if student's perceptions of individuals with disabilities changed since participating in the disability awareness activities, or if their perceptions had remained the same.

\subsection{Participants}

Participants were recruited using convenience sampling of all available fifth grade classrooms at a local elementary school. The tool used to collect data included a standardized, reliable, and valid assessment, CATCH. This assessment was utilized through a pretest and posttest questionnaire. A total of 54 students participated in the study by taking both a pretest and post- test $\mathrm{CATCH}$ assessment and by receiving the Whitehorse Kit intervention activities. All participants had varying levels of knowledge about what disability means and had various exposure to those with disabilities. Some individuals had siblings or family members with a disability, whereas other individuals had little to no knowledge about what a disability is.

\subsection{Procedures}

Data was collected by six Shenandoah University (SU) Occupational Therapy (OT) students and under the supervision of two faculty members. The students administered a pretest, educational teaching plan, and then a posttest to 54 fifth grade students. In order to obtain study participants, the students reached out to the elementary school's guidance counselor and worked with her to facilitate the study. Prior to conducting research, assent and consent was from the parents/guardians as well as the 5th grade students. An International Review Board application (IRB) was submitted and approved by the SU IRB.

The SU OT students administered a pretest about perceptions and knowledge of disability awareness in an inclusive classroom through the use of the modified CATCH assessment. The intervention was the implementation of a disability awareness education plan through the use of The White House Learning Disability Kit over the span of four 
weeks. After the conclusion of the disability awareness education activities, a posttest $(\mathrm{CATCH})$ was administered.

\section{Results}

A total of 54 students participated in all parts of this study. SPSS was used to analyze the data collected. The pre and post-test $\mathrm{CATCH}$ scores were measured using a paired sample Wilcoxon t-test with the p-value set at 0.05 .

The pretest scores ranged from 11.40 to 38.20 with a median pretest score of 28.80. A higher total score indicates an overall more positive attitude towards others with a disability (with a maximum score of 40). The posttest scores ranged from 14.70 to 39.70 with a median posttest score of 29.30 (Table 1). With a Z-score of -3.353 , the results indicated statistical significance of .001 . Of the fifty-four participants, thirty-seven demonstrated an increase in posttest scores, sixteen decreased in posttest scores, and one did not show any change in scores (Table 2).

Table 1. CATCH Descriptive statistics.

\begin{tabular}{lllll}
\hline & N & Minimum & Maximum & Median \\
\hline PreTest & 54 & 11.40 & 38.20 & 28.8 \\
PostTest & 54 & 14.70 & 39.70 & 29.3 \\
\hline
\end{tabular}

Table 2. CATCH Pre/Post Results Wilcoxon Signed Ranks Test.

\begin{tabular}{llll}
\hline Posttest-Pretest & N & Mean Rank & Sum of Ranks \\
\hline Negative Ranks & $16^{\mathrm{a}}$ & 21.06 & 337.00 \\
Positive Ranks & $37^{\mathrm{b}}$ & 29.57 & 1094.00 \\
Ties & $1^{\mathrm{c}}$ & & \\
Total & 54 & & \\
\hline
\end{tabular}

Key: a. posttest $<$ pretest b. posttest $>$ pretest c. posttest $=$ pretest.

\section{Discussion}

Results from the study indicated a positive change in the perceptions and attitudes of participants after administration of the Whitehorse Disability Kit lessons over the course of four weeks. The scores taken from the CATCH assessment, pre-test and post-test, demonstrated a change in median scores from 28.8 to 29.3 . While the score appears to be minimal, statistical significance was achieved at 0.001 using a Wilcoxon paired sample t-test. The study utilized activities from the Whitehorse Disability Kit to increase student attitudes and perceptions of peers with disabilities. The change in scores after activities from The White Horse Disability Kit indicates positive changes in student attitudes and perceptions.

This study supports previous similar research as the attitudes and perceptions of children with disabilities increased after implementing four weeks of lesson plans. This study demonstrates the positive impact of incorporating disability awareness programs in the school system. The preand post-test CATCH scores increased for the majority of students, which indicates an increase in positive attitudes towards peers. Implementing activities like the ones in this study has the potential to lead to students being more likely to interact with peers with disabilities, and thus increasing future positive involvement and interactions with individuals with disabilities.

Future research of this kind could be implemented over a longer period of time and with larger samples sizes and differing student populations in multiple contexts. This would allow for a better understanding of the longer term effect of activity exposure among a larger and more diverse student population.

\section{Conclusion}

The Whitehorse Disability Kit provided activities that facilitated change in the attitudes and perceptions of peers with disabilities among fifty-four fifth grade students at a primary school in rural Virginia. Utilizing the Whitehorse Disability Kit, along with interactive presentations and activities, yielded greater receptivity and positive perceptions after the interventions. Fifth grade represents a pivotal time to educate individuals about what 'disability' means before the transition to middle school years. The participants were receptive and excited to have the four lessons and expressed increased understanding about disability. Students can develop a greater understanding about disability, and this study illustrates a good and easy opportunity to integrate this type of education into the school system curriculum.

\section{References}

[1] World Health Organization. (2014, December 16). World report on disability. Retrieved from http://www.who.int/disabilities/world_report/2011/report/en/.

[2] Katsiyannis, A., Yell, M., \& Bradley, R. (2001). Reflections on the 25th anniversary of the individuals with disabilities education act. Remedial and Special Education, 22, 324-334.

[3] Lindsay, S., \& McPherson, A. C. (2012). Strategies for improving disability awareness and social inclusion of children and young people with cerebral palsy. Child: Care, Health \& Development, 38 (6), 809-816. doi: 10.1111/j.13652214.2011.01308.x

[4] Bates, H., McCafferty, A., Quayle, E., \& McKenzie, K. (2015). Review: Typically-developing students' views and experiences of inclusive education. Disability \& Rehabilitation, $37 \quad$ (21), 1929-1939. https://doi.org/10.3109/09638288.2014.993433.

[5] Lindsay, S., \& Edwards, A. (2013). A systematic review of disability awareness interventions for children and youth. Disability \& Rehabilitation, 35 (8), 623-646. doi: 10.3109/09638288.2012.702850.

[6] Ison, N., McIntyre, S., Rothery, S., Smithers-Sheedy, H., Goldsmith, S., Parsonage, S., \& Foy, L. (2010). 'Just like you': a disability awareness programme for children that enhanced knowledge, attitudes and acceptance: pilot study findings. Developmental Neurorehabilitation, 13 (5), 360-368. doi: 10.3109/17518423.2010.496764. 
[7] Novak, A. and Barthelheim, F. J. (2012). General Education Students' Changing Perceptions of Students with Special Needs. Current Issues in Education, v15 n2.

[8] Campbell, J., Gilmore, L., \& Cuskelly, M. (2009). Changing student teachers' attitudes towards disability and inclusion. Journal of Intellectual \& Developmental Disability, 28 (4), 369-379. doi: 10.1080/13668250310001616407.

[9] Moore, D. and Nettelbeck, N. (2013). Effects of short-term disability awareness training on attitudes of adolescent schoolboys toward persons with a disability. Journal of Intellectual \& Developmental Disability, 38 (3).

[10] Whitehorse City Council Disability Awareness Kit (2005). Accessed here: https://www2.whitehorse.vic.gov.au/ignitionsuite/uploads/doc s/Disability\%20Awareness\%20Resource\%20Kit.pdf

[11] ADA (2020). Definitions of Disability under ADA. Accessed February 2020 here: https://adata.org/faq/what-definitiondisability-under-ada.

[12] Kover, S. (2018). Distributional Cues to Language Learning in Children With Intellectual Disabilities. Language, Speech, and Hearing Services in School, 49, 653-667.

[13] Kim, J., Kim, M., \& Han, A. (2018). Exploring the Relationship between Types of Leisure Activities and Life Satisfaction, Health Perception, and Social Support among Korean Individuals with Physical Disabilities. American Journal of Health Behavior, 42 (4), 34-44.

[14] Wilis, C., Reid, S., Elliot, C., Rodenberg, M., Nyquist, A., Jahnsen, R, Girdler, S. (2018). A realist evaluation of a physical activity participation intervention for children and youth with disabilities: what works, for whom, in what circumstances, and how? Willis et al. BMC Pediatric, 18. 10.1111/dmen.12326.

[15] De Boer, A., Pijl, S., \& Minnaert, A. (2012). Students' attitudes, experiences, and perspectives on their peers with disabilities. International Journal of Disability Development and Education, 59 (4), 379-392. doi: $10.1080 / 1034912 X .2012 .723944$.
[16] McKay, C., Block, M., \& Jung Yeon, P. (2015). The Impact of Paralympic School Day on Student Attitudes Toward Inclusion in Physical Education. Adapted Physical Activity Quarterly, 32 (4), 331-348. doi: 10.1123/APAQ.2015-0045.

[17] Macmillan, M., Tarrant, M., Abraham, C., \& Morris, C. (2013). The association between childrens contact with people with disabilities and their attitudes towards disability: A systematic review. Developmental Medicine \& Child Neurology, 56 (6), 529-546. doi: 10.1111/dmcn.12326.

[18] Scior, K., Addai-Davis, J., Kenyon, M., \& Sheridan, J. C. (2012). Stigma, public awareness about intellectual disability and attitudes to inclusion among different ethnic groups. Journal of Intellectual Disability Research. doi: 10.1111/j.1365-2788.2012.01597.x.

[19] Rillotta, F., \& Nettelbeck, T. (2007). Effects of an awareness program on attitudes of students without an intellectual disability towards persons with an intellectual disability. Journal Of Intellectual \& Developmental Disability, 32 (1), 19-27.

[20] Mu, K., Brown, T., Peyton, C., Rodger, S., Huang, Y., Wu, C., \& ... Hong, C. (2010). Occupational therapy students' attitudes towards inclusion education in Australia, United Kingdom, United States and Taiwan. Occupational Therapy International, 17 (1), 40-52. doi: 10.1002/oti.285

[21] Hartley, M. T., Bauman, S., Nixon, C. L., \& Davis, S. (2015). Comparative Study of Bullying Victimization Among Students in General and Special Education. Exceptional Children, 81 (2), 176-193. doi: 10.1177/0014402914551741.

[22] Vignes C, Coley N, Grandjean H, Godeau E, \& Arnaud C. (2008). Measuring children's attitudes towards peers with disabilities: a review of instruments. Developmental Medicine \& Child Neurology, 50 (3), 182-189.

[23] Bossaert, G., \& Petry, K. (2013). Factorial validity of the Chedoke-McMaster Attitudes towards Children with Handicaps Scale (CATCH). Research in Developmental Disabilities, $34 \quad$ (4), 1336-1345. https://doiorg.suproxy.su.edu/10.1016/j.ridd.2013.01.007 